\title{
Load and thermal characteristics of a conveyor device for infrared drying and cleaning seeds
}

\author{
Aleksey Zavaliy ${ }^{1}$, Sergey Volozhaninov ${ }^{1, *}$, Olga Shiian $^{1}$, Dmitriy Rudoy ${ }^{2}$, Anastasiya \\ Olshevskaya $^{2}$ \\ ${ }^{1}$ V.I. Vernadsky Crimean Federal University, 4, prosp. Vernadskiy, 295492, Simferopol, Russia \\ ${ }^{2}$ Don State Technical University, 1, Gagarin square, 344000, Rostov-on-Don, Russia
}

\begin{abstract}
It is offered the conveyor device that provides an atraumatic and energy-efficient effect on seeds. It is determined the energy-mechanical indicators of the operation of the main device units and it is given the recommendations for the optimization. It is analyzed the results of the thermal effect of infrared radiation on the drying seeds process.
\end{abstract}

\section{Introduction}

Agricultural production is one of the most important and complex industries. Sustainable production of field crops is a prerequisite for economic stability and food security of the South of Russia, which the soil and climatic conditions allow to produce high quality seed. A special place in the technological process of cultivation of agricultural crops plays a postharvest treatment of seed, the improvement of technology which enables to reduce losses and improve quality and technological properties of the product.

Nowadays the means of mechanization and post-harvest technologies of seeds are presented as complexes and individual machines which based on the mechanical and thermal effects on the processed material. It isn't paid enough attention to the issues of combining the sparing noninvasive effects on seeds, energy saving, resource saving and environmental safety. However, seeds are exposed to shock, abrasion and high pressure during the transportation. There are some methods and modes of thermal seeds treatment which are used in many cases but they aren't enough substantiated, they are characterized by high levels of non-uniformity and it is determined the lack of efficiency of the applied design and technological solutions. These methods and modes affect significantly the quality of the seeds after treatment [1 - 15].

The aim of the study is the creation of resource-saving mechanization and mechanized ecologically safe technologies of primary processing and preparation for seed crops storage, elite seed primarily.

\section{Material and research methods}

The studies were carried out at V.I. Vernadsky Crimean Federal University on the experimental infrared drying and seed cleaning conveyor device (Figure 1), designed and

* Corresponding author: s.volozhaninov@mail.ru 
manufactured by us in accordance to the indicators which characterize the efficiency of resource conservation and environmental safety: the maximum reproductive ability of seeds for providing it we use non-traumatic methods of moving seeds and "soft" modes of uniform heat treatment, it is not allowed seeds overheating and bunks sewing the integrity of the seed coat with high temperature stresses; it is ensured the low specific energy for heat treatment in the case of the environmentally safe use of energy sources; low cost of equipment provided by the use of "non-rigid" equipment elements and "non-rigid" connections between elements; the universal equipment in relation to raw materials and its initial properties; low operating costs for repairs, replacement of components and maintenance.

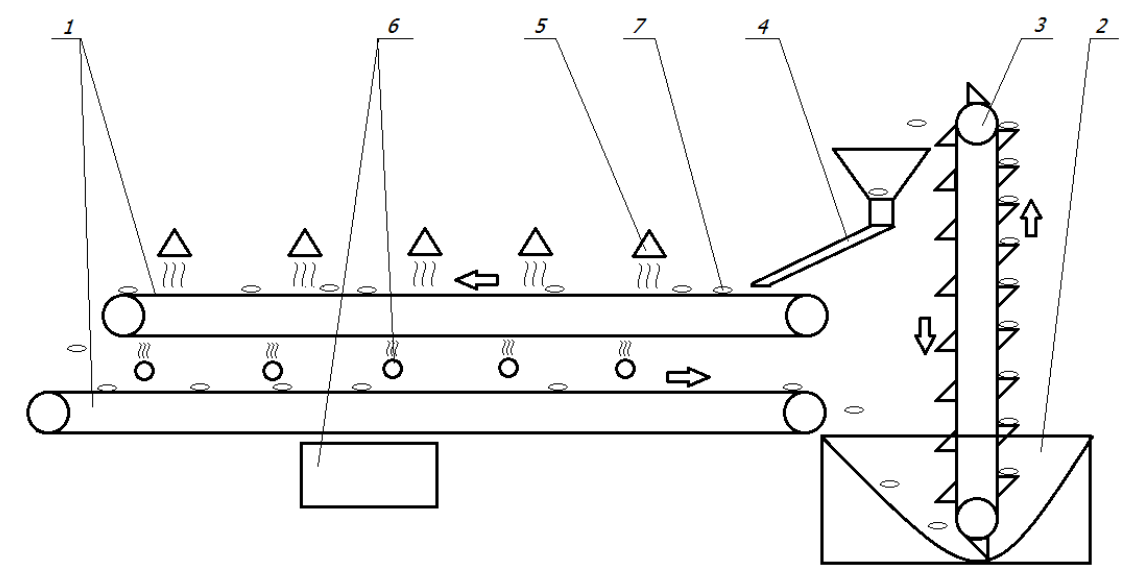

Fig. 1. Schematic diagram of a conveyor device for infrared drying and seed cleaning: 1 - main conveyor; 2 - storage hopper; 3 - elevator; 4 - dispensing unit; 5 - infrared emitters; 6 - ventilation system; 7 - seeds.

Conveying device operates as follows. Seeds with initial moisture content poured into the hopper 2 from it through the elevator 3 seeds are transported to the dispensing unit 4, ensuring the distribution of seeds in width of the ribbon of the main conveyor. Then the seeds are moved by the main conveyor and pass under the infrared emitters 5 , at the same time after heat exposure, with some horizontal offset, the seeds are subjected to air blowing through ventilation system 6. After passing through the upper branches of the main conveyor, the seeds are poured on the lower branch and transported back to the hopper 2 . Then the process occurs again periodically, until the seeds have the necessary humidity.

The energy performance of the conveyor device infrared drying and cleaning of seeds are determined by the cost of transportation of seeds in the course of their treatment and the cost of energy of infrared radiation sources and the ventilation system [16].

To determine the cost of transportation of seeds it is examined the conveyor load characteristics of mechanical part. In the first stage of the research it was carried out a computer modeling of geometrical and kinematic parameters of the elevator and transfer devices, determining the uniformity of loading of the tape main conveyor and providing atraumatic movement of seeds. For establishing the calculation of operational parameters of the elevator and the boot device it was experimentally determined the energy to the actuator assemblies and mechanisms for actual consumption of electricity. The energy cost of the power sources of infrared radiation and ventilation system was determined in the experiment by measuring the change of mass and moisture content of helianthus seeds during drying in the movement of seeds on the ribbon of the main conveyor.

The algorithm of the experiment includes the following steps:

- for weighing seeds weighing 1,500 to 2,000 grams, their relative humidity is determined;

- if it is necessary, the seeds are moistened with water with a household spray to a relative 
humidity of $10-11 \%$, after calculating the amount of moisture which is necessary for introducing into the seeds;

- a moistened sample is placed on the upper conveyor belt of the main conveyor in the section of the dispensing unit into the frame with dimensions of $1450 \times 220 \mathrm{~mm}$ and a layer with a thickness of $15-20 \mathrm{~mm}$;

- after turning on the infrared emitters and the ventilation system, the upper belt is set in motion and the seeds are transferred under the heat and air to collect the tray which is located at the outlet of the upper conveyor branch;

- the seeds collected in the tray are weighed on an analytical balance and their relative humidity is determined, then the seeds are again placed in a frame placed at the beginning of the upper branch of the conveyor;

- the process is repeated until the desired seed moisture is reached.

The temperature of the seeds is measured at the points of loading and unloading of the upper belt of the main conveyor using a non-contact pyrometer; it should not exceed the temperature regime requirements for processing seed $40^{\circ} \mathrm{C}[1-6]$. The obtained data are processed using descriptive statistics methods.

\section{Results and discussion}

For modeling the movement of seeds to the bucket elevators it is used the balance equation of the centrifugal force and gravity acting on the seed during its circular motion around the axis of the upper (drive) drum (1):

$$
m \frac{d^{2} x}{d \tau^{2}}=m \omega^{2} x-m g \sin \alpha
$$

where is $m$ - the mass of seed, $\mathrm{kg}$;

$x$ - the radial coordinate of the seed position, $\mathrm{m}$;

$\tau$ - time, s;

$\omega$ - the angular velocity of rotation of the drive drum, $\mathrm{s}^{-1}$;

$g-$ acceleration of free fall, $\mathrm{m} / \mathrm{s}^{2}$;

$\alpha$ - the angle of rotation of the bucket elevator, rad.

The result of numerical modeling determined that for unstressed bulk movement of seed rotation speed of the upper drive drum must not exceed $6 \mathrm{~s}^{-1}$, and, accordingly, the linear speed of the conveyor drum should not be greater than $0.9 \mathrm{~m} / \mathrm{s}$ (Figure 2). The graphs indicated by the dotted line are radius of the drive drum, the dashed line indicates the radius of the path described by the edges of the buckets, and the solid line is the trajectory of the seed. From Figure 2 it is seen that for the selected initial data with angular speed $6 \mathrm{~s}^{-1}$ the seed is shifted by a distance not exceeding the radial height, which is not coming from the surface of the ladle and poured in further rotation to the surface of the preceding bucket elevators. The linear conveyor speed does not exceed $0.9 \mathrm{~m} / \mathrm{s}$ at the angular speed greater than $6 \mathrm{~s}^{-1}$, the seed remains on the surface of the bucket and then moves under the action of forces of inertia and gravity. As it is shown by the path of inertial movement of the seed, the seed after some time returns to the "corridor" of movement of the buckets, but further movement trajectory may include the impact on the surface of the bucket and rebound from it that must be eliminated to move the seed [17-18]. 


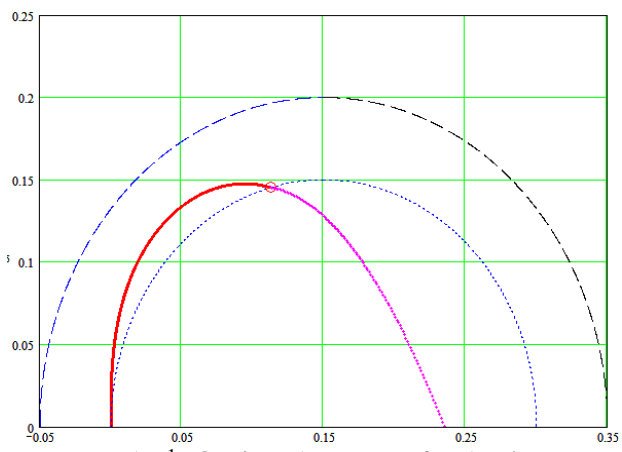

$\omega=5 \mathrm{~s}^{-1} ; \Omega=47,75 \mathrm{rpm} ; \mathrm{V}=0,75 \mathrm{~m} / \mathrm{s}$

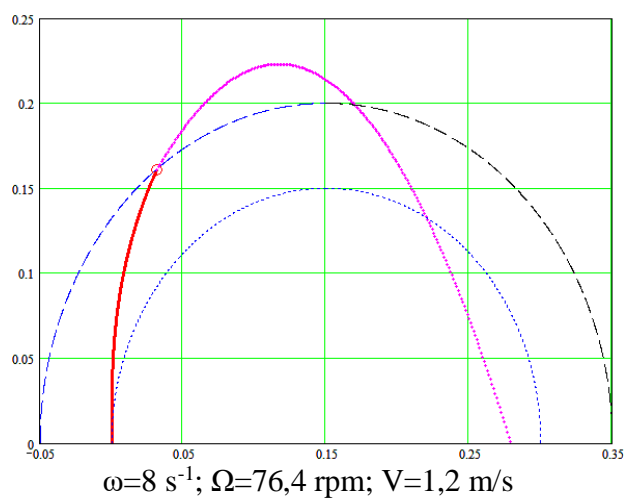

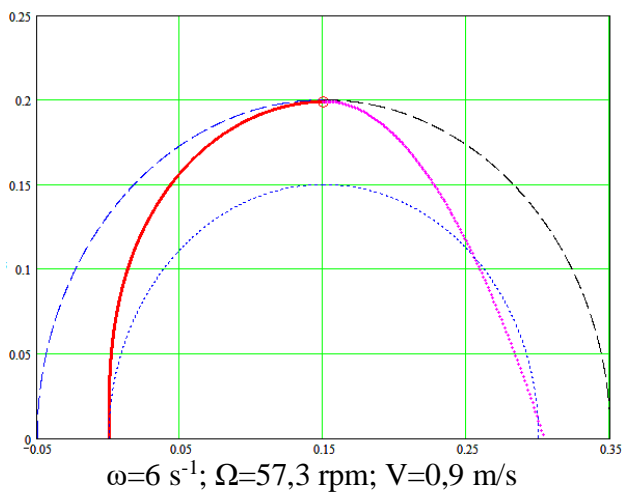

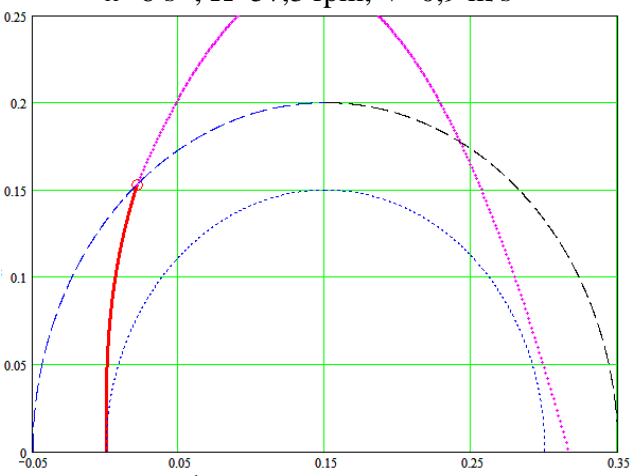

$\omega=10 \mathrm{~s}^{-1} ; \Omega=95,5 \mathrm{rpm} ; \mathrm{V}=1,5 \mathrm{~m} / \mathrm{s}$

Fig. 2. The calculated trajectories of the seed for a given angular speed of the drive drum $\omega$, the rotation frequency of the drive drum $\Omega$, linear velocity $\mathrm{V}$.

One of the technically difficult tasks of ensuring the operability of an infrared drying conveyor device is the uniform supply of seeds of various crops and initial moisture to the belt of the main conveyor along the width of the belt. We have developed a rotary feeder design and a reciprocating type of carriage movement. The computational modeling of the movement of the dispensing unit was carried out taking into account the fact that the seeds are supplied to the carriage from the outlet groove according to the equation of the balance of forces acting on the seed during its movement along the inclined groove, making an angular reciprocating movement in a plane located at an angle to the horizon:

$$
m \frac{d^{2} x_{1}}{d \tau^{2}}=m \omega_{1}^{2}(\tau) x_{1}-m g \cos \left(\alpha_{1}(\tau)\right)-f\left(m g \sin \left(\alpha_{1}(\tau)\right)+2 m \omega_{1}(\tau) \frac{d x_{1}}{d \tau}\right.
$$

where is $m$ - the mass of seed, $\mathrm{kg}$;

$x_{1}-$ seed movement in a coaxial pipe, $\mathrm{m}$;

$\tau$ - time,s;

$\omega_{1}$ - angular rotation speed of the coaxial nozzle, $\mathrm{s}^{-1}$;

$g$-acceleration of gravity, $\mathrm{m} / \mathrm{s}^{2}$;

$\alpha_{1}$ - the angle of inclination of the coaxial pipe in relation to the vertical, rad.

The output chute is a coaxial pipe of variable length, which is carrying out the turning movement in the plane defined by the line of carriage movement of the distributing node and the center of the outlet bulk cap elevators. Computational analysis was applied to establish the dependence of the uniformity of the layout of seeds to feed the main conveyor from the feeding of seeds and the linear speed of movement of the carriage and the conveyor belts, as well as analysis of the seed trajectory the exit of the coaxial nozzle, depending on the coaxial tube length and angle, the linear speed of carriage movement and seeds supply. 
It was found that the speed of movement of the main conveyor tape of $0.06 \mathrm{~m} / \mathrm{s}$ the speed of the carriage movement in the range of $1.5-2.0 \mathrm{~m} / \mathrm{s}$ to ensure uniform coating of the conveyor belt seeds; the speed of movement of the carriage in the range of 1 to $2 \mathrm{~m} / \mathrm{s}$ does not lead to significant differences in the exit speed of seeds from the coaxial nozzle at different angular positions (Figure 3). The graphs on the $\mathrm{x}$-axis were postponed length, and the ordinate of the main conveyor belt width [19].

For the above ranges of speeds of the belt and the carriage transfer unit were performed by the experimental determination of the uniformity of seeds distribution of wheat, helianthus and coriander on the width of the main conveyor tape. The result is that the uneven distribution of seeds is 15 to $35 \%$, the busiest central part of the belt, the uniformity of the distribution depends on the crop type of the treatment and the seeds supply to the ribbon, the uniform distribution does not depend on the kinematic characteristics of the elevator and the hand-knot, uniformity of distribution of seeds along the conveyor belt surface which is determined by speed belt.

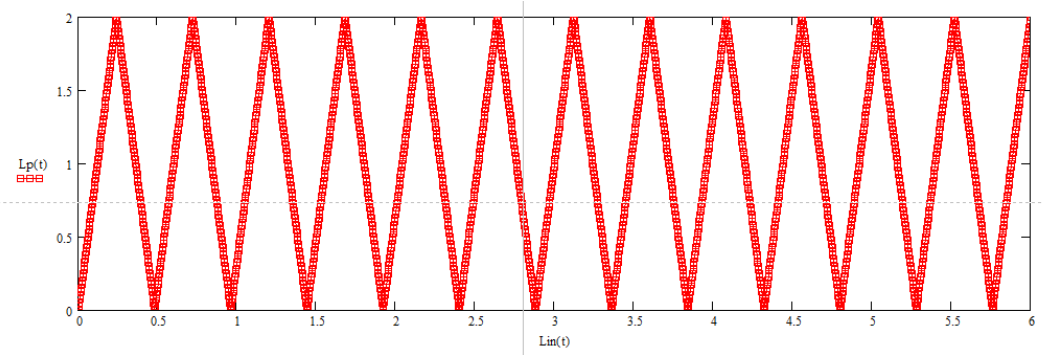

calculated trajectory of the layout of seeds at a carriage speed of $0.5 \mathrm{~m} / \mathrm{s}$

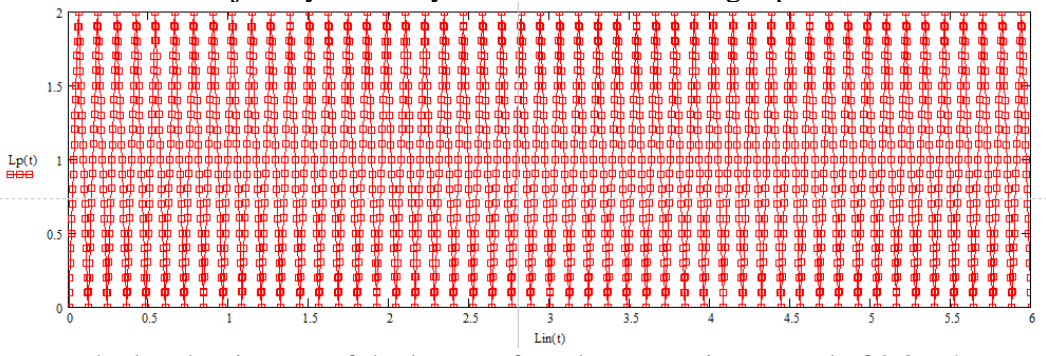

calculated trajectory of the layout of seeds at a carriage speed of $2.0 \mathrm{~m} / \mathrm{s}$

Fig. 3. The results of computational modeling on the distribution of helianthus and wheat seeds on the belt of the main conveyor.

The results of an experimental study of the cost of power to drive the main conveyor, elevator and distributing unit when processing wheat, helianthus, and coriander are shown in Table 1.

Table 1. Energy costs for the drive of the mechanical part of the conveyor device, $\mathrm{kW} \cdot$ hour.

\begin{tabular}{|c|c|c|c|}
\hline \multirow{2}{*}{ Unit } & \multicolumn{3}{|c|}{ Cultivated plant } \\
\cline { 2 - 4 } & $\begin{array}{c}\text { wheat } \\
\mathbf{1 2 0 0} \mathbf{~ k g} / \mathbf{h}\end{array}$ & $\begin{array}{c}\text { helianthus } \\
\mathbf{9 6 0} \mathbf{~ k g} / \mathbf{h}\end{array}$ & $\begin{array}{c}\text { coriander } \\
\mathbf{1 0 8 0} \mathbf{~ k g} / \mathbf{h}\end{array}$ \\
\hline Main conveyor & 0.70 & 0.25 & 0.20 \\
\hline Distribution unit, elevator & 0.40 & 0.50 & 0.50 \\
\hline
\end{tabular}

Analyzing the obtained data, it can be noted the power on the drive of the dispenser and elevator does not depend on the processed crop. Moreover, the power to drive the main conveyor increases depending on the specific gravity of the seeds of the processed crops.

An experimental investigation is connected with changes in the mass and relative 
humidity of helianthus seeds during drying and it was performed at a linear conveyor belt speed of $0.116 \mathrm{~m} / \mathrm{s}$. Seeds during drying were under the thermal irradiation of 5 sources with a power consumption of $2000 \mathrm{~W}$ each, placed in cross sections of the tape with a pitch of $1000 \mathrm{~mm}$ with a total length of the upper branch of the conveyor $6200 \mathrm{~mm}$. The results of the experimental determination of changes in the mass and moisture of the seeds are shown in Figure 4, 5. Drying was performed at the initial seed moisture in the range of $8.5-9.5 \%$ to a final moisture value of $6 \%$.

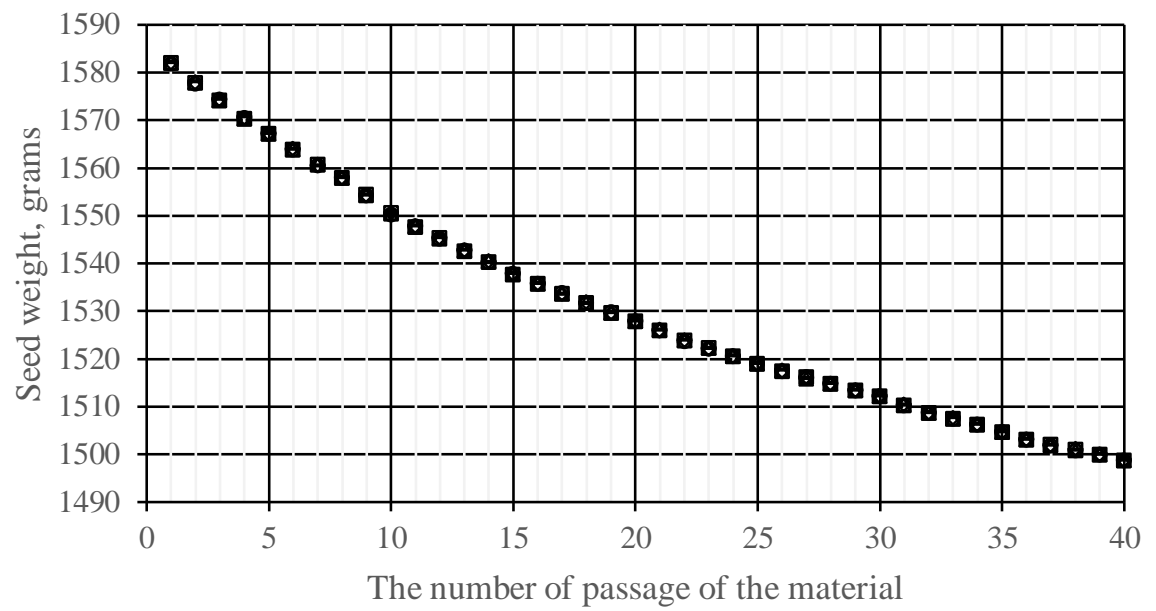

Fig. 4. Mass dynamics.

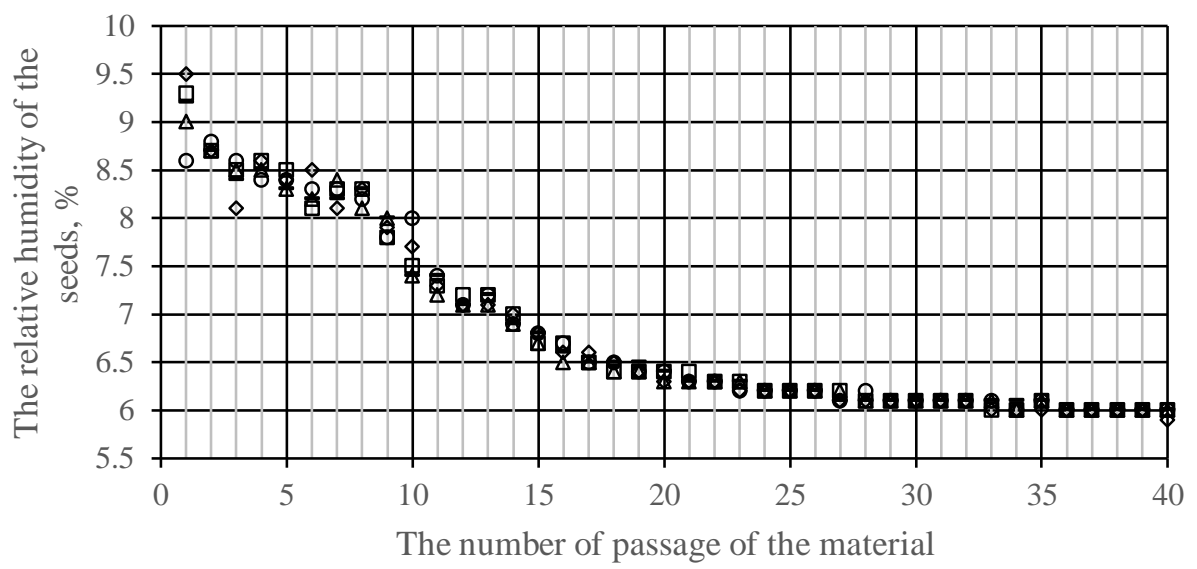

Fig. 5. The dynamics of relative humidity of helianthus.

Under the specified conditions for the movement of seeds and the total power consumption of infrared emitters $10 \mathrm{~kW}$, it is necessary to perform 35 - 40 passes to achieve the given final data of the relative seeds humidity.

\section{Conclusions}

A calculated analysis of the seeds movement and the experimental investigation of the uniformity of the supply of seeds to the conveyor belt proved that shock-free bulk seeds flow 
in a vertical conveyor provides a drum rotation speed not more than $6 \mathrm{~s}^{-1}$, and, accordingly, the linear conveyor belt speed of not more than $0.9 \mathrm{~m} / \mathrm{s}$. The uneven layout in the cross section of the conveyor belt is from 15 to $35 \%$ with the most loaded central part of the conveyor belt.

Depending on the being processed crop and the device loading, the power consumption of the drive unit of the conveyor mechanical part is $0.70-1.10 \mathrm{~kW}$.

The selected layout scheme provides the necessary conditions for ensuring the surface temperature of the seeds during the drying process, not higher than $40{ }^{\circ} \mathrm{C}$. Energy costs for IR drying of seeds in the moisture range from $10.5 \%$ to $6 \%$ are $0.335 \mathrm{~kW} \cdot \mathrm{h} / \mathrm{kg}$ of seeds. When drying in the humidity range from $10.5 \%$ to $8.5 \%$ (decrease in humidity by $2 \%$ ), costs are reduced to $0.05 \mathrm{~kW} \cdot \mathrm{h} / \mathrm{kg}$. Further drying from $8.5 \%$ to $6.5 \%$ humidity requires a cost of $0.1 \mathrm{~kW} \cdot \mathrm{h} / \mathrm{kg}$, and from $6.5 \%$ to $6 \%$ humidity $0.185 \mathrm{~kW} \cdot \mathrm{h} / \mathrm{kg}$.

Thus, the experimental infrared drying and seed dressing conveyor with a total power consumption of $11 \mathrm{~kW}$ provides the reduction in seed moisture from 10.5 to $8.5 \%$ at a productivity of $200 \mathrm{~kg} / \mathrm{h}$ and specific energy consumption of $0.05 \mathrm{~kW} \cdot \mathrm{h} / \mathrm{kg}$ of seeds. A reduction in humidity from 8.5 to $6.5 \%$ reduces productivity and doubles the specific energy consumption.

\section{References}

1. S. Mehran, M. Nikian, M. Ghazi, H. Zareiforoush, I. Bagheri, Solar Energy 19015.9, 167-184 (2019)

2. C. Ding, R. Khir, Z. Pan, Z. Pan, D.F. Wood, J. Berrios, Food Chemistry 26430.10, 149156 (2018)

3. N.K. Rastogi, Reference Module in Food Science (2019)

4. Y. Mizutani, M. Shibata, S. Yamada, Y. Nambu, Y. Matsumura, Food Chemistry 2751.3, 577-584 (2019)

5. E.J. Rifna, K. Ratish Ramanan, R. Mahendran, Trends in Food Science \& Technology 86.4, 95-108 (2019)

6. S. Wei, Z. Wang, F. Wang, W. Xie, D. Yang, Food and Bioproducts Processing 117.9, 360-372 (2019)

7. H. Rahmanian- Koushkaki, A. Nourmohamadi- Moghadami, D. Zare, Engineering in Agriculture, Environment and Food 10.3.7, 191-197 (2017)

8. S. Ruhanian, K. Movagharnejad, Engineering in Agriculture, Environment and Food 9.1.1, 84-91 (2016)

9. H. Chaji, M. Hedayatizadeh, Engineering in Agriculture, Environment and Food 10.3.7, 178-185 (2017)

10. E.-H. Lee, Reference Module in Food Science (2020)

11. N.N. Chen, M.Q. Chen, B.A. Fu, J.J. Song, Energy 12115.2, 726-738 (2017)

12. D. Yogendrasasidhar, Y. PydiSetty, Energy 15115.5, 799-811 (2018)

13. D.I. Onwude, N. Hashim, G. Chen, Trends in Food Science \& Technology 57.A.9, 132145 (2016)

14. G.G. Atungulu, S. Sadaka, Rice (Fourth Edition), 473-515 (2019)

15. Xiao-fei Wu, Min Zhang, Zhongqin Li, LWT 111.8, 790-798 (2019)

16. Yu.A. Ivanov, V.I. Pakhomov, S.I. Kambulov, D.V. Rudoi, MATEC Web of Conferences (ICMTMTE 2018), 05023 (2018)

17. E.P. Klyuchka, V.V. Radin, L.M. Groshev, S.I. Kambulov, MATEC Web of Conferences, 02020 (2018) 
18. S.I. Kambulov, V.B. Rykov, E.I. Trubilin, Research Journal of Pharmaceutical, Biological and Chemical Sciences 9.4, 599-606 (2018)

19. A. Altybayev, A. Zhanbyrbayev, B. Meskhi, E3S Web of Conferences, https://doi.org/10.1051/e3sconf/201913501078 